\title{
Labour market discrimination against former juvenile delinquents: evidence from a field experiment
}

\begin{abstract}
In view of policy action to integrate ex-offenders into society, it is important to identify the underlying mechanisms of the negative relationship between criminal record on the one hand and later employment and earnings on the other hand. In this study, we identify hiring discrimination against former juvenile delinquents in a direct way. To this end, we conduct a field experiment in the Belgian labour market. We find that labour market discrimination is indeed a major barrier in the transition to work for former juvenile delinquents. Labour market entrants disclosing a history of juvenile delinquency get about 22 percent less callback compared to their counterparts without a criminal record. This discrimination is heterogeneous by the occupation for which one applies.
\end{abstract}

\section{Introduction}

Former contributions have been giving evidence for a causal negative relationship between criminal record on the one hand and later employment and earnings on the other hand (Lott, 1990; Waldfogel, 1994; Grogger, 1995; Needels, 1996; Borland and Hunter, 2000; Western et al., 2001; Kling, 2006; Graffam et al., 2008; Holzer, 2009; Apel and Sweeten, 2010; Dominguez Alvarez and Loureiro, 2012). This finding is important as this labour market sanction for crime is an important component of 
overall punishment (Holzer, 2009). These adverse labour market outcomes among former ex-offenders may have important well-being effects: unemployed are less happy (satisfied with their life) than employed (Dolan et al., 2008; Stiglitz et al., 2009; Helliwell et al., 2012). ${ }^{1}$ Moreover, limited work opportunities may also encourage exoffenders to return to crime (Needels, 1996; Raphael and Weiman, 2007; Wu and Wu, 2012).

In view of policy action to integrate ex-offenders into society, it is important to identify the underlying mechanisms of the aforementioned relationship between criminal record and later labour market outcomes. Is the negative association between criminal record and later labour market outcomes fully explained by supply side factors such as differences in worker productivity, work interest and work networks between ex-offenders and non-offenders (Waldfogel, 1994; Kling, 2006; Holzer, 2009; Apel and Sweeten, 2010)? Or does it also reflect employer discrimination so that the adverse labour market effects of criminal record are at least partly out of control of the ex-offender? In this paper we identify hiring discrimination against juvenile delinquents in Belgium using a correspondence test.

Former contributions have been giving theoretical grounds for and ethical elaborations on labour market discrimination against former juvenile delinquents.

${ }^{1}$ Knabe and Rätzel (2011a) calculate that the well-being costs of unemployment are about two times higher than its pecuniary costs. The meta-analysis from McKee-Ryan et al. (2005) indicates that these well-being cost are higher for young people than for unemployed adults. Besides the impact of current unemployment on current well-being, there is also a "scarring-effect of unemployment" (Clark et al., 2001): past unemployment reduces current levels of well-being. Knabe and Rätzel (2011b) and Lange (2013) explain this scarring effect by the fear of future unemployment. 
From a theoretical point of view labour discrimination against ex-offenders might be consistent both with taste discrimination as induced by, for instance, customer discrimination, co-worker discrimination and prejudices about trustworthiness and with statistical discrimination as induced by potentially lower (average) levels of productivity among offenders (Becker, 1957; Arrow, 1973; Holzer et al., 2007). From an ethical point of view one can discuss the responsibility of the juvenile. (How long) should one hold someone responsible for criminal facts in the past? Some egalitarian theories "consider it legitimate to put individuals in such a situation that they may seriously suffer from their own decisions" (Fleurbaey, 2005, p.29). Holding people responsible for past choices means that those having worse employment opportunities as a consequence of a criminal background have no right to help. Such an approach can be criticised as being too harsh as it does not take into account how regretful someone is (or can be) about past decisions (Fleurbaey, 2005). We investigate the probability of getting hired (or the probability of discrimination) when someone is honest about this criminal past. When we would discover a lower hiring probability, the ethical question of responsibility and help (or not) becomes relevant indeed.

Direct empirical evidence on labour market discrimination against ex-offenders is scarce. Recently, the sociologist Devah Pager identified substantial measures of unequal treatment based on criminal record in the United States (Pager, 2003; Pager et al., 2009a; Pager et al., 2009b). In his studies teams of actors were matched and sent to apply for low-wage jobs in New York presenting equivalent resumes and differing only in their (race and) criminal background. We complement their research results by means of a pure correspondence test, in the spirit of Bertrand and Mullainathan (2004). The advantages of using this method are discussed in Section II. Moreover, this section 
describes our research design in detail. Section III presents our research results. Section IV concludes and discusses the (policy) implications of our results.

\section{Methodology}

Measuring Unequal Treatment by a Field Experiment

Most former contributions on the relationship between criminal history on the one hand and labour market outcomes on the other hand are based on non-experimental data. These non-experimental studies focus mainly on earnings and/or employment differentials by criminal record based on survey or administrative data (Lott, 1990; Grogger, 1995; Needels, 1996; Borland and Hunter, 2000; Western et al., 2001; Kling, 2006; Apel and Sweeten, 2010; Dominguez Alvarez and Loureiro, 2012). In general, they suffer from two important statistical problems: unobserved heterogeneity and sample selection bias. First, job applicants who appear similar to researchers (except for their criminal history) based on (standard) non-experimental data, might look very different to employers. As long as not all relevant variables taken into account by employers in making their hiring, remuneration and promotion decisions, are controlled by the researcher, no conclusive proof of discrimination can be provided. Second, it is possible that individuals with better economic outcomes - who may be more confident in their interaction both with interviewers and colleagues - are more willing to disclose their status as an ex-offender. This leads to an upwards bias of the measured outcomes of ex-offenders. In addition, the studies focussing on wage differentials may suffer from the non-random selection into employment of employees 
with and without a criminal history. Wage regressions may understate the full effects of unequal treatment based on criminal history by leaving out the fact that potentially many applicants with such a history are barred from even earning a wage. In order to overcome these methodological problems, field experiments can be conducted. These experimental methods provide a powerful mean of isolating causal mechanisms. Two options are described in the literature: correspondence tests and audit tests (Riach and Rich, 2002; Pager, 2007).

Correspondence experiments testing for hiring discrimination on grounds such as ethnicity, gender, beauty and sexual orientation have been extensively used and refined during the last century (Bertrand and Mullainathan, 2004; Petit, 2007; Rooth, 2009; Drydakis, 2011). Within these correspondence tests, pairs of fictitious written job applications are sent to real job openings. The two applications within each pair are similar, except for the single characteristic that is to be tested. By monitoring the subsequent callback, that is the reaction from the employer side, unequal treatment based on this characteristic can be identified. These field experiments have been widely viewed as providing the most convincing evidence of unequal treatment in hiring decisions (Riach and Rich, 2002). With a correspondence test selection on the basis of individual unobservable characteristics is eliminated since all the information received by the employer is controlled by the researcher. Thereby, strict equivalence between fictitious applicants is ensured and employer discrimination is disentangled from alternative explanations of differential hiring rates such as differential employee preferences and network effects.

A drawback of correspondence tests is that they investigate the first stage in the hiring process only. Since only callback rates for first interviews are measured, one 
cannot make statements about discrimination in the later stages of the selection process, let alone in wages or promotion opportunities. ${ }^{2}$ So called audit studies go one step further by sending matched pairs of actors to apply for jobs presenting equivalent resumes and differing only in the discrimination ground. This approach was used in the studies by Pager (2003), Pager et al. (2009a) and Pager et al. (2009b) in the context of hiring discrimination based on criminal record. However, recently researchers have been criticising this method based on various grounds (Heckman and Siegelman, 1993; Heckman, 1998; Riach and Rich, 2002; Weichselbaumer, 2013). A main critique is that audit studies suffer from the problem that it may be impossible to find and successfully train real-life job applicants so that they truly represent a perfect match. In addition, auditors may consciously or subconsciously be motivated to prove discrimination and adjust their behaviour accordingly in an interview. Last, from an ethical point of view, the time investment in respect of the employers is substantial in the case of audit tests. ${ }^{3}$ As correspondence tests circumvent the latter problems, we setup a correspondence test aimed at answering our research question. To the best of our knowledge we are the first to apply this experimental methodology in the context of

${ }^{2}$ However, Bertrand and Mullainathan (2004) argue that to the extent that the selection process has even moderate frictions, one would expect that reduced interview rates would translate into reduced job offers and lower earnings. Moreover, since job interviews are costly, firms invite applicants for an interview only if they have a reasonably high chance of getting the job.

${ }^{3}$ For an in-depth discussion of the strengths and weaknesses of field experiments aimed at identifying discrimination in the labour market, we refer to Riach and Rich (2002), Bertrand and Mullainathan (2004) and Pager (2007). For an elaboration on the ethical aspects of these kinds of experiments, we refer to Riach and Rich (2004). 
unequal treatment based on criminal history.

Our experiment was conducted between December 2012 and April 2013 in Flanders, the northern and economically more prosperous half of Belgium. Two fictitious applications of school-leavers, identical except that one mentioned a period of juvenile delinquency, were sent out to each of 486 vacancies for labour market entry jobs. All these vacancies were taken from the database of the public employment service of Flanders (VDAB), which is the major job search channel in Flanders. From this database, we randomly selected vacancies of private employers in three (middle-) low-skilled occupations (manual worker, barkeeper and nanny) and three (middle-) high-skilled occupations (electrical engineer, representative and social worker). Including several occupations rather than just one is important since by focussing on a single occupation, as was done in some of the aforementioned correspondence tests, the researcher may just pick an occupation where discrimination is large. Furthermore, by including on the one hand both jobs in which money handling is on average high (barkeeper and representative) versus low (manual worker, nanny, electrical engineer and social worker) and on the other hand both jobs in which responsibility for (the health and safety of) other people is high (nanny and social worker) versus low (manual worker, barkeeper, electrical engineer and representative), we are able to investigate heterogeneity in unequal treatment along these job characteristics.

\section{Construction of Fictitious Applications}

We created two template types (Type 'A' and Type 'B') of resumes and cover letters for each of the six occupations listed earlier in this section, each matching the general requirements of these occupations. Type A and Type B applications were, at the level 
of the occupation, identical in all job-relevant characteristics but differed in inessential details and in lay-out. Several example applications of the VDAB, with different fonts and layouts, were used and calibrated for our purposes, so that our applications were realistic and representative.

All fictitious applicants were single males, born, living and studying in one of the suburbs of Antwerp, the largest city of Flanders. Low-educated school-leavers were 18 years old and high-educated school-leavers were 21 years old. They all graduated from the same type of school, with a comparable reputation, in June 2012. None of the applicants experienced grade retention. The low-educated applicants applying for the occupations of manual worker, barkeeper and nanny held a secondary education degree in mechanics, tourism and health and welfare sciences respectively. The higheducated applicants applying for the occupations of electrical engineer, representative and social worker held a professional bachelor in electronics, business administration and social work. ${ }^{4}$

In addition we added to all applications the following features: Belgian nationality, Dutch mother tongue, adequate French and English language skills, driving licence, computer skills and summer employment experience. The cover letters indicated a person who was highly motivated and well organised. For the high-skilled applicants, sports club membership and student leadership were also added. Finally, we appended a fictitious postal address (based on real streets in middle-class neighbourhoods) and a date of birth to all applications. The resume and cover letter templates are available on

\footnotetext{
${ }^{4}$ The former three degrees correspond to the ISCED 3 level, the latter three to the ISCED 5 level. ISCED stands for International Standard Classification of Education.
} 
request.

Revelation of Juvenile Delinquency

In Belgium, the anti-discrimination law (2007) stipulates some prohibited grounds for unequal treatment such as gender, race, age and sexual orientation. Having a criminal background is not legally recognised as a prohibited ground, which implies that the legislation "allows" rejecting someone on the basis of a criminal background. Some protection is offered as the applicant is not obliged to mention his criminal past to his future employer. Juvenile delinquency is registered in the Central Criminal Register but does not appear on the extract from the municipal criminal register (an extract that the employer can ask for). Information from the Central Criminal Register cannot be shown to anybody unless the person in question grants permission. ${ }^{5}$

We sent two applications, one of Type A and one of Type B, to each selected vacancy. In one member of each pair the applicant disclosed a history of juvenile delinquency. This was done by including the following clause in the cover letter: "In view of a trustful collaboration I wish to report that during my secondary education career I spent one year at an open detention centre ${ }^{6}$ because of juvenile delinquency. However, this period is for me a thing of the past and I have a certificate of good conduct". The fact that we mentioned an "open" detention centre is important in view

\footnotetext{
${ }^{5}$ There are exceptions for certain public functions.

${ }^{6}$ Placement in an open detention centre is only possible from the age of 12 years on, for specific situations stipulated by law: (1) crimes that if they were committed by adults would cause an imprisonment of at least three years or (2) an act categorised as assault and battery (Van Rumst, 2007).
} 
of the school career without grade retention included in the applications. Besides, underlining that the applicant had a certificate of good conduct was needed as lacking this certificate could give the employer an objective ground (in the present) to reject this applicant. In what follows we will point at this applicant as the "former juvenile delinquent".

In the other member of each pair, we did not mention any information related to criminal record. In what follows we will point at this applicant as the "control applicant". Of course, this presumably "clean" applicant could also be an ex-offender in disguise who did not want to disclose his criminal record. Therefore, the comparison of the former juvenile delinquent and the control applicant actually identifies the costs associated with disclosing the status of former youth delinquent.

In order to eliminate any possible effect on callbacks of the application type, we alternately assigned the clause disclosing juvenile delinquency to the Type A and Type B applications. Subsequently, we sent the resulting combinations in an alternating order to the employers, each time with about 24 hours in between.

\section{Measurement of Callback}

We registered two email addresses and mobile phone numbers, one for the individual without revealed juvenile delinquency and one for the individual with revealed juvenile delinquency. ${ }^{7}$ All applications were sent to the employer by email. In order to

7 We chose "Simon De Boeck" and "Bert Vandaele" as the names of the (low- respectively higheducated) control applicants and "Dieter Van Acker" and "Kristof De Muynck" as the names of the former juvenile delinquents. We checked that these names did not represent a difference in socio- 
avoid detection, we applied to no more than one vacancy from the same employer.

Callbacks were received by telephone voicemail or email. The content of the responses is available on request. Since we included postal addresses with a nonexistent street number in the applications, we could not measure callback by regular mail. However, several human resource managers confirmed that nowadays employers rarely, if ever, invite job applicants by regular mail for selection interviews. To minimise inconvenience to the employers, we immediately declined invitations to job interviews. All callbacks received later than 30 days after sending out the application were discounted (this, however, turned out to be an unnecessary restriction since we hardly received any positive callback after 30 days). In line with former correspondence experiments aimed at identifying hiring discrimination based on other grounds than criminal history, we define positive callback as the situation in which the applicant gets an invitation for a job interview, an alternative job proposal or the request to provide more information or to contact the recruiter.

\section{Results}

\section{Positive callback by criminal record}

Table 1 presents our main statistical results based on the experimental dataset. In line with Riach and Rich (2002), we provide the reader with two statistical measures: the 
net discrimination rate and the positive callback ratio. Since two applications were sent to each vacancy there are four possible outcomes: (i) positive callback for neither applicant, (ii) positive callback for both applicants, (iii) positive callback only for the control applicant and (iv) positive callback only for the former juvenile delinquent applicant. Overall, Panel A of Table 1 shows that in 105 of the 486 vacancies at least one applicant received a positive callback. 39 cases resulted in a positive callback for just the control applicant and 20 for the former juvenile delinquent only. The net discrimination rate is calculated by reducing the number of applications for which the control applicant was preferred by the number of applications for which the former juvenile delinquent applicant was preferred and this difference is then divided by the number of application pairs in which at least one received a positive callback. Overall this net discrimination rate is 0.18 . Based on a standard $\chi^{2}$-test, the hypothesis that both applicants were equally often treated unfavourably is rejected. In about one out of five applications for which at least one candidate got a positive callback, the applicants disclosing a period of juvenile delinquency could expect to encounter discriminatory acts.

\section{TABLE 1 ABOUT HERE.}

The positive callback ratio is obtained by dividing the percentage of applications for which control applicants received a positive callback by the corresponding percentage for the former juvenile delinquent applicants. The value for this statistic

presented in Table 1 (Panel A) confirms the finding based on the net discrimination 
rate. Overall, the positive callback rate is $0.17^{8}$ for control applicants and 0.14 for former juvenile delinquents. The resulting positive callback ratio is 1.29 , indicating that the control applicants got $29 \%$ more positive callback compared with their counterparts not revealing a criminal history. This ratio is significantly different from one at the 5\% significance level. In conclusion, overall, both the net discrimination rate and the callback ratio point at substantial levels of discrimination of former juvenile delinquents in the occupations tested in the Belgian labour market. As by construction observable characteristics are equal for both applicants for each vacancy, regression analysis leads to the same statistical conclusions.

\section{Heterogeneity of unequal treatment by occupation and gender of the recruiter}

Next, we break down the net discrimination rate and the callback ratio to the occupation level (Table 1, Panel B). Doing so shows that discrimination against former juvenile offenders is higher than average in the occupations of barkeeper and electrical engineer, and about average (but statistically no longer significant due to the small sample size) in the occupations of manual worker and nanny. For the occupation of representative, we do not find any unequal treatment. Last, for the occupation of social worker we find weakly significant evidence for positive discrimination towards exoffenders. We believe that this may be related to the fact that employers see juvenile delinquency as an experience that is relevant from the perspective of this job. If we aggregate the positive callback ratio over the low-skilled and high-skilled occupations, we get a higher ratio for the former occupations (1.54) than for the latter occupations

\footnotetext{
${ }^{8} 0.17=(46+39) / 486$.
} 
(1.13). This finding squares with the general theoretical and empirical evidence for a negative relationship between unequal treatment in hiring and the level of education of the applicant. ${ }^{9}$ Moreover in our specific empirical setup, juvenile delinquency during secondary education is longer ago for higher education. This empirical finding, however, contrasts to some extent with Waldfogel (1994) who finds, using panel data estimations on administrative data, that the negative effect of conviction on income is especially important for those who are highly educated.

Last, we inspect whether discrimination is heterogeneous by the gender of the contact person in the vacancy (Table 1, Panel C). While among female recruiters overall no unequal treatment is found, we find significant levels of discrimination against applicants with a background of juvenile delinquency in respect of male recruiters. This finding is consistent with Carlsson and Rooth (2007) providing evidence for higher levels of ethnic discrimination among male recruiters (compared with female recruiters) in Sweden. However, as the regression analysis in the next subsection will learn, we cannot reject that the difference in callback ratio by the recruiter's gender is significantly different from zero.

\section{Regression analysis}

As, by construction, we randomised over the disclosure of former juvenile delinquency by the fictitious job applicants, regressing positive callback on this disclosure (and

\footnotetext{
${ }^{9}$ From a theoretical point of view Taubman and Wales (1974) argue that higher education can act as a prejudices reducing screening device. Recent empirical for this relationship has been given by Bursell (2007), Carlsson and Rooth (2007) and Baert et al. (Forthcoming).
} 
vacancy and employee characteristics) leads to the same empirical conclusion as the one based on Panel A of Table 1. On the other hand, the occupation and recruiter gender variables may correlate with each other and with other vacancy characteristics and, therefore, the results presented in Panel B and Panel $\mathrm{C}$ of Table 1 may in fact reflect heterogeneity of unequal treatment based on juvenile delinquency by other dimensions. Moreover, due to the finite nature of our data selection, the occupation and gender of the recruiter variables may even correlate with the application type (A or B) to which the former juvenile delinquent was assigned and with whether his application was sent before or after the control applicant. Therefore, we further explore the experimentally gathered data by regressing, by means of a linear probability model, the outcome of positive callback on criminal background and various sets of variables which are included as such and in interaction with disclosure of former juvenile delinquency. The results of this analysis are outlined in Table 2. For reasons of comparability of the regression results, except for "juvenile delinquency", all variables are normalised by subtracting their mean among the subpopulation of former delinquents and, for the continuous variables, by dividing the result by the standard deviation among this subpopulation.

\section{TABLE 2 ABOUT HERE.}

First, in models (1), (2) and (3), we regress positive callback on former delinquency (model (1)), former delinquency, occupation dummies interacted with former delinquency and occupation dummies without interaction (model (2)) and former delinquency, dummies indicating the recruiter's gender interacted with former delinquency and dummies indicating the recruiter's gender without any interaction 
(model (3)). By construction, the estimations presented in columns (1), (2) and (3) reflect those presented in Panel A, Panel B and Panel C of Table 1. For instance, based on column (1), we learn that revealing former juvenile delinquency lowers the chance on positive callback with about four percentage points, which squares with the comparison of the callback rates for "treated" and control candidates based on Panel A of Table 1 as mentioned earlier in this section. Furthermore, column (2) indicates that unequal treatment is significantly less to the detriment of former delinquents in the occupations of representative and social worker compared to the (reference) occupation of barkeeper. Second, in model (4), we combine the explanatory variables included in model (2) and model (3). This hardly affects the estimation results as the correlation between the occupations and the gender of the recruiter is rather low (Cramer's V = 0.19).

Third, in model (5), which is our benchmark regression model, we extend the set of independent variables included (as such and in interaction with disclosure of former juvenile delinquency). On the one hand, we include variables indicating Type B applications and applications that were the first one of the pair sent to the vacancy. On the other hand, we include sector dummies and the number of (comparable) jobs announced in the vacancy. Concerning the sector of the firm, we use the Statistical Classification of Economic Activities in the European Community ("NACE") at the 2digit-level. ${ }^{10}$ Introducing these variables lowers the significance of the interactions

\footnotetext{
${ }^{10}$ The sector code was, based on the name and the address of the firm mentioned in the vacancy, found in the databases of the Flemish business magazine Trends and the Belgian organisation of Self-
} 
between former delinquency and the occupations of representative and social worker due to the correlation between the occupation and sector dummies - if the latter dummies (main effects and interaction effects) are left out of the regression model, the estimated coefficients for the occupation dummies are closely comparable to those in column (4). Furthermore, we see that unequal treatment was weakly less to the detriment of former delinquents when they applied with the Type B application, which is not a problem given our randomisation strategy.

Fourth, in model (6) we substitute the occupation dummies by three dummies capturing characteristics of these occupations, namely the skill-level and the degree of money handling and responsability for other people. However, none of the regression coefficients for these variables interacted with former delinquency is significant. Therefore, we cannot confirm the descriptive evidence of less discrimination of former delinquents in high-skilled positions as provided in the former subsection. Fifth, in model (7) we extend the set of explanatory variables included in model (5) with a proxy of the size of the firm, i.e. the natural logarithm of the average number of workers (in full-time equivalents) employed by this firm in $2010 .{ }^{11}$ We were not able to obtain this proxy for each firm tested in our experiment, so that including this

Employed and Small and Medium Sized Enterprises UNIZO. In total, 57 sectors are represented in the data.

${ }^{11}$ This proxy was obtained from the Bel-first database (Bureau Van Dijk), based on the name of the firm mentioned in the vacancy and/or its company number (found in the aforementioned databases of Trends and UNIZO). 
variable decreases the number of observations in model (7) with $15 \% .^{12}$ As reviewed by Baert and Balcaen (2013), former contributions to the empirical literature on hiring discrimination reported lower rates of unequal treatment in large companies. In our case, however, the estimated coefficient for the firm size proxy has the expected (negative) sign, but is not significant. By including this variable, the interactions between former delinquency on the one hand and the occupation of representative and using a Type B application on the other hand become insignificant.

\section{Heckman and Siegelman's critique}

As a final analysis, we test the robustness of our main finding, i.e. statistically significant evidence of hiring discrimination against job candidates who reveal a history of juvenile delinquency, using a heteroskedastic probit model. We do this given Heckman and Siegelman's (1993) critique of previous correspondence studies. This critique boils down to the fact that not controlling for group differences in the variance of unobservable determinants of positive callback can lead to substantial bias. The solution to this problem is, as recently proposed by Neumark (2012), to adopt a heteroskedastic probit model, allowing the variance of the error term to vary with the minority status of the applicants, in our case the disclosure of former delinquency. We identify this heteroskedastic probit model, in the spirit of Baert et al. (Forthcoming), by assuming that the distance between the fictitious applicant's living place and the workplace mentioned in the vacancy has the same effect on the callback of former juvenile delinquents and control applicants. From an empirical point of view, the

\footnotetext{
${ }^{12}$ This is the reason why we do not include this variable in benchmark model (5).
} 
hypothesis that the coefficient for this variable is equal across both groups cannot be rejected on the basis of a likelihood ratio test. By running this heteroskedastic probit model, however, we find no significant difference in the variance of the error term between the two groups classified by juvenile delinquency history (the p-value of the likelihood ratio test is 0.90 ) so that the results presented in the former sections are not biased by the problem described in Heckman and Siegelman (1993).

\section{Discussion and Conclusion}

This paper joins in with former evidence for a negative relationship between criminal record and later employment. More concretely, we identify hiring discrimination against juvenile delinquents in Belgium in a direct way. By using a correspondence test we avoid the problem of selection on the basis of characteristics that are unobservable to the researcher using non-experimental data. Two similar applications of labour market entrants, one of both revealing a period of youth delinquency, were sent out each to 486 ads for jobs requiring no experience. Half of them were sent to jobs for relatively low-educated and half of them to jobs for relatively high-educated. Furthermore, as the sources underlying labour market discrimination might be more prominent for some types of jobs than for others, we distinguished between jobs with and without responsibility towards other people and between jobs with and without financial responsibility. By monitoring the callback from the employer side we find that labour market discrimination is indeed a major barrier in the transition to work for former youth delinquents. This discrimination is heterogeneous by the occupation for which one applies. Regression analysis shows, however, that this dimension of 
heterogeneity is less pronounced after controlling simultaneously for heterogeneity by the sector of the firm.

As labour market discrimination based on criminal grounds imposes collateral costs on ex-offenders, on their families and communities and on the society (e.g., direct and indirect costs induced by recidivism), one might consider to explicitly incorporate past criminal record as a prohibited ground for unequal treatment in the labour market, which is for the moment not the case in Belgium and many other OECD countries. However the issue of personal responsibility impedes that this is an obvious decision. On the one hand free individuals can make choices and have to bear the consequences of their choices. In this line of reasoning it should not be seen as problematic that individuals who opted for criminal activities end up with lower employment probabilities. On the other hand real freedom also implies the freedom to change preferences (Vansteenkiste et al., 2012). Fleurbaey (2005) therefore argues in favour of some "forgiveness" (i.e. the possibility to take a fresh start) for individuals who truly regret past decisions. As the absence of recidivism is an unmistakably indication that the preferences have been modified, there is no moral hazard problem ${ }^{13}$ in this case. One could thus argue in favour of incorporating a past criminal record as a prohibited ground for unequal treatment as a "forgiving" policy.

\footnotetext{
${ }^{13}$ In some cases it is not possible to distinguish between those who really changed their preferences and those who say they have changed (see, e.g., Vansteenkiste et al. (2012) for an elaboration on this idea in the context on an unhealthy lifestyle).
} 


\section{References}

Apel, R. and Sweeten, G. (2010) The Impact of Incarceration on Employment during the Transition to Adulthood. Social Problems, 57, 448-479.

Arrow, K. J. (1973) The Theory of Discrimination. Princeton University Press, New Jersey.

Baert, S. and Balcaen, P. (2013) The Impact of Military Work Experience on Later Hiring Chances in the Civilian Labour Market. Evidence from a Field Experiment. Economics: The Open-Access, Open-Assessment E-Journal, 7, 2013-37.

Baert, S., Cockx, B., Gheyle, N. and Vandamme, C. (Forthcoming) Is there Less Discrimination in Occupations where Recruitment is Difficult? Industrial and Labor Relations Review.

Becker, G. S. (1957) The economics of discrimination. University of Chicago Press, Chicago.

Bertrand, M. and Mullainathan, S. (2004) Are Emily and Greg more employable than Lakisha and Jamal? A field experiment on labor market discrimination. American Economic Review, 94, 991-1013.

Bloothooft, G. and Onland, D. (2011) Socioeconomic determinants of first names. Names 59, 25-41.

Borland, J. and Hunter, B. (2000) Does crime affect employment status? The case of indigenous Australians. Economica, 67, 123-144.

Bursell, M. (2007) What's in a name? A field experiment test for the existence of ethnic discrimination in the hiring process. Stockholm University Linnaeus 
Center for Integration Studies Working Paper Series, 7.

Carlsson, M. and Rooth, D.-O. (2007) Evidence of ethnic discrimination in the Swedish labor market using experimental data. Labour Economics, 14, 716729.

Clark, A. E., Georgellis, Y. and Sanfey, P. (2001) Scarring: The Psychological Impact of Past Unemployment. Economica, 68, 221-241.

Dolan, P., Peasgood, T. and White, M. (2008) Do we really know what makes us happy? A review of the economic literature on the factors associated with subjective well-being. Journal of Economic Psychology, 29, 94-122.

Dominguez Alvarez, R. and Loureiro, M. L. (2012) Stigma, Ex-convicts and Labour Markets. German Economic Review, 13, 470-486.

Drydakis, N. (2011) Sexual orientation and labour relations: new evidence from Athens, Greece. Applied Economics, 44, 2653-2665.

Fleurbaey, M. (2005) Freedom with forgiveness. Politics, Philosophy and Economics, 4, 29-67.

Graffam, J., Shinkfield, A. J. and Hardcastle, L. (2008) The perceived employability of ex-prisoners and offenders. International Journal of Offender Therapy and Comparative Criminology, 52, 673-685.

Grogger, J. (1995) The Effect of Arrests on the Employment and Earning of Young Men. Quarterly Journal of Economics, 110, 51-71.

Heckman, J. (1998) Detecting discrimination. Journal of Economic Perspectives, 12, 101-116.

Heckman, J. and Siegelman, P. (1993) The Urban Institute audit studies: Their methods and findings, in Clear and Convincing Evidence: Measurement of 
Discrimination in America, (Eds) M. Fix and R. J. Struyk, The Urban Institute, Washington, DC.

Helliwell, J., Layard, R. and Sachs, J. (2012) World Happiness Report. The Earth Institute, New York.

Holzer, H. J. (2009) Collateral Costs, The Effects of Incarceration on the Employment and Earnings of Young Workers, in Do Prisons Make Us Safer? The Benefits and Costs of the Prison Boom, (Eds) S. Bushway, M. A. Stoll and D. Weiman Russell Sage Foundation, New York.

Holzer, H. J., Raphael, S. and Stoll, M. A. (2007) The Effect of an Applicant's Criminal History on Employer Hiring Decisions and Screening Practices: Evidence from Los Angeles, in (Eds) Barriers to Reentry? The Labor Market for Released Prisoners in Post-Industrial America, S. Bushway, M. A. Stoll and D. Weiman, Russell Sage Foundation, New York.

Kling, J. R. (2006) Incarceration Length, Employment, and Earnings. American Economic Review, 96, 863-876.

Knabe, A. and Rätzel, S. (2011a) Quantifying the psychological costs of unemployment: the role of permanent income. Applied Economics, 43, 27512763.

Knabe, A. and Rätzel, S. (2011b) Scarring or Scaring? The Psychological Impact of Past Unemployment and Future Unemployment Risk. Economica, 78, 283-293.

Lange, T. (2013) Scarred from the past or afraid of the future? Unemployment and job satisfaction across European labour markets. The International Journal of Human Resources Management, 24, 1096-1112.

Lott, J. R. (1990) The Effect of Conviction on the Legitimate Income of Criminals. 
Economics Letters, 34, 381-385.

McKee-Ryan, F., Song, Z. and Wanberg, C. R. (2005) Psychological and Physical Well-Being During Unemployment: A Meta-Analytic Study. Journal of Applied Psychology, 90, 53-76.

Needels, K. E. (1996) Go directly to jail and do not collect? A long-term study of recidivism, employment, and earnings patterns among prison releases. Journal of Research in Crime and Delinquency, 33, 471-496.

Neumark, D. (2012) Detecting Discrimination in Audit and Correspondence Studies. Journal of Human Resources, 47, 1128-1157.

Pager, D. (2003) The mark of a criminal record. American Journal of Sociology, 108, 937-975.

Pager, D. (2007) The use of field experiments for studies of employment discrimination: contributions, critiques, and directions for the future. Annals of the American Academy of Political and Social Science, 609, 104-133.

Pager, D., Western, B. and Bonikowski, B. (2009a) Discrimination in a Low-Wage Labor Market: A Field Experiment. American Sociological Review, 74, 777799.

Pager, D., Western, B. and Sugie, N. (2009b) Sequencing Disadvantage: Barriers to Employment Facing Young Black and White Men with Criminal Records. Annals of the American Academy of Political and Social Science, 623, 195-213.

Petit, P. (2007) The effects of age and family constraints on gender hiring discrimination: A field experiment in the French financial sector. Labour Economics, 14, 371-391.

Raphael, S. and Weiman, D. (2007) The Impact of Local Labor-Market Conditions on 
the Likelihood that Parolees Are Returned to Custody, in (Eds) Barriers to Reentry? The Labor Market for Released Prisoners in Post-Industrial America, S. Bushway, M. A. Stoll and D. Weiman, Russell Sage Foundation, New York. Riach, P. A. and Rich, J. (2002) Field Experiments of Discrimination in the Market Place. Economic Journal, 112, 480-518.

Riach, P. A. and Rich, J. (2004) Deceptive Field Experiments of Discrimination: Are They Ethical? Kyklos, 57, 457-470.

Rooth, D.-O. (2009) Obesity, Attractiveness, and Differential Treatment in Hiring: A Field Experiment. Journal of Human Resources, 44, 710-735.

Stiglitz, J. E., Sen, A. and Fitoussi, J.-P. (2009) Report by the Commission on the measurement of economic performance and social progress. Commission on the Measurement of Economic Performance and Social Progress, Paris.

Taubman, P. J. and Wales, T. (1974) Higher Education and Earnings: College as an Investment and Screening Device. NBER Books, Massachusetts.

Van Rumst, S. (2007) Jongeren in detentie, het verblijf in gemeenschapsinstellingen. Retrieved from www.jeugdrecht.be, article 2007-10.

Vansteenkiste, S., Devooght, K. and Schokkaert, E. (2012) Beyond individual responsibility for lifestyle: granting a fresh and fair start to the regretful. HUB Research papers, 2012/4.

Waldfogel, J. (1994) The Effect of Criminal Conviction on Income and the Trust 'Reposed in the Workmen'. Journal of Human Resources, 24, 62-81.

Weichselbaumer, D. (2013) Testing for Discrimination against Lesbians of Different Marital Status: A Field Experiment. IZA Discussion Paper Series, 7424.

Western, B., Kling, J. R. and Weiman, D. F. (2001) The Labor Market Consequences 
of Incarceration. Crime and Delinquency, 47, 410-427.

$\mathrm{Wu}, \mathrm{D}$. and $\mathrm{Wu}, \mathrm{Z}$. (2012) Crime, inequality and unemployment in England and Wales. Applied Economics, 44, 3765-3775. 
Table 1. Data Description

\begin{tabular}{|c|c|c|c|c|c|c|c|c|c|}
\hline Occupations & $\begin{array}{l}\text { Jobs } \\
\text { (No.) } \\
\end{array}$ & $\begin{array}{l}\text { Neither } \\
\text { applicant } \\
\text { positive } \\
\text { callback } \\
\text { (No.) } \\
\end{array}$ & 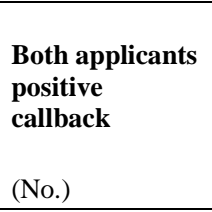 & $\begin{array}{l}\text { Only control } \\
\text { applicant } \\
\text { positive } \\
\text { callback } \\
\text { (No.) } \\
\end{array}$ & $\begin{array}{l}\text { Only former } \\
\text { juvenile } \\
\text { delinquent } \\
\text { positive } \\
\text { callback } \\
\text { (No.) } \\
\end{array}$ & $\begin{array}{l}\text { Net } \\
\text { discrimination } \\
\text { rate }\end{array}$ & $\chi^{2}$ & $\begin{array}{l}\text { Positive } \\
\text { callback ratio }\end{array}$ & $t$ \\
\hline \multicolumn{10}{|l|}{ A. All observations } \\
\hline All observations & 486 & 381 & 46 & 39 & 20 & $0.18 * *$ & 6.12 & $1.29 * *$ & 2.49 \\
\hline \multicolumn{10}{|c|}{ B. Heterogeneity by occupation } \\
\hline Manual worker & 79 & 67 & 2 & 6 & 4 & 0.17 & 0.40 & 1.33 & 0.63 \\
\hline Barkeeper & 80 & 63 & 5 & 10 & 2 & $0.47 * *$ & 5.33 & $2.14 * *$ & 2.37 \\
\hline Nanny & 80 & 56 & 6 & 11 & 7 & 0.17 & 0.89 & 1.31 & 0.94 \\
\hline Electrical engineer & 83 & 57 & 16 & 9 & 1 & $0.31 * *$ & 6.40 & $1.47^{* * *}$ & 2.62 \\
\hline Representative & 80 & 65 & 9 & 3 & 3 & 0.00 & 0.00 & 1.00 & 0.00 \\
\hline Social worker & 84 & 73 & 8 & 0 & 3 & $-0.27 *$ & 3.00 & $0.73^{*}$ & 1.75 \\
\hline \multicolumn{10}{|c|}{ C. Heterogeneity by the gender of the recruiter } \\
\hline Female recruiter & 271 & 203 & 34 & 20 & 14 & 0.09 & 1.06 & 1.13 & 1.03 \\
\hline Male recruiter & 161 & 132 & 9 & 15 & 5 & $0.34 * *$ & 5.00 & $1.71 * *$ & 2.27 \\
\hline
\end{tabular}

Notes: The net discrimination rate is calculated by reducing the number of applications for which the control applicant was preferred by the number of applications for which the former juvenile delinquent applicant was preferred and this difference is then divided by the number of application pairs in which at least one received a positive callback. The $\chi^{2}$-test for the net discrimination rate tests the null hypothesis that both applicants are treated unfavourably just as frequently. $* * *$ indicates significance at the $1 \%$ significance level, $* *$ at the $5 \%$ significance level and $*$ at the $10 \%$ significance level. The positive callback ratio is calculated by dividing the percentage of applications for which control applicants received a positive callback by the corresponding percentage for former juvenile delinquent applicants. The $t$-test for the positive callback ratio tests the null hypothesis that the probability of a positive answer is the same for applicants from both groups. As two applicants contacted the same firm, the probability of the control applicant receiving an invitation was correlated with the probability of the former delinquent receiving one. Therefore, standard errors are corrected for clustering of firm, the probability of the control applicant receiving an invitation was correlated with the probability of the former delinquent receiving one. Therefore, standard errors are corrected for clustering of
the observations at the vacancy level. *** indicates significance at the $1 \%$ significance level, $* *$ at the $5 \%$ significance level and * at the $10 \%$ significance level. The number of jobs with a male or a female recruiter does not equal the total number of jobs as for some vacancies we could not identify the gender of the contact person. 
Table 2. Regression Results.

\begin{tabular}{|c|c|c|c|c|c|c|c|}
\hline & (1) & (2) & (3) & (4) & (5) & (6) & (7) \\
\hline Juvenile delinquency & $\begin{array}{l}-0.039 * * \\
(0.016)\end{array}$ & $\begin{array}{l}-0.039 * * \\
(0.016)\end{array}$ & $\begin{array}{l}-0.039 \text { ** } \\
(0.016)\end{array}$ & $\begin{array}{l}-0.039^{* *} \\
(0.016)\end{array}$ & $\begin{array}{l}-0.039^{* *} \\
(0.016)\end{array}$ & $\begin{array}{l}-0.039 * * \\
(0.016)\end{array}$ & $\begin{array}{l}-0.039 * * \\
(0.017)\end{array}$ \\
\hline Juvenile delinquency $x$ Occupation: manual worker & & $\begin{array}{l}0.075 \\
(0.058)\end{array}$ & & $\begin{array}{l}0.068 \\
(0.059)\end{array}$ & $\begin{array}{l}0.225 \\
(0.143)\end{array}$ & & $\begin{array}{l}0.162 \\
(0.144)\end{array}$ \\
\hline Juvenile delinquency x Occupation: nanny & & $\begin{array}{l}0.050 \\
(0.068)\end{array}$ & & $\begin{array}{l}0.041 \\
(0.068)\end{array}$ & $\begin{array}{l}0.146 \\
(0.121)\end{array}$ & & $\begin{array}{l}0.158 \\
(0.123)\end{array}$ \\
\hline Juvenile delinquency x Occupation: electrical engineer & & $\begin{array}{l}0.004 \\
(0.056)\end{array}$ & & $\begin{array}{l}-0.001 \\
(0.058)\end{array}$ & $\begin{array}{l}0.190 \\
(0.139)\end{array}$ & & $\begin{array}{l}0.144 \\
(0.142)\end{array}$ \\
\hline Juvenile delinquency x Occupation: representative & & $\begin{array}{l}0.100 * \\
(0.052)\end{array}$ & & $\begin{array}{l}0.097^{*} \\
(0.053)\end{array}$ & $\begin{array}{l}0.260^{*} \\
(0.136)\end{array}$ & & $\begin{array}{l}0.195 \\
(0.138)\end{array}$ \\
\hline Juvenile delinquency x Occupation: social worker & & $\begin{array}{l}0.136 * * * \\
(0.052)\end{array}$ & & $\begin{array}{l}0.130^{* * * *} \\
(0.048)\end{array}$ & $\begin{array}{l}0.217^{*} \\
(0.117)\end{array}$ & & $\begin{array}{l}0.212^{*} \\
(0.125)\end{array}$ \\
\hline Juvenile delinquency $\mathrm{x}$ High-educated & & & & & & $\begin{array}{l}0.051 \\
(0.038)\end{array}$ & \\
\hline Juvenile delinquency $x$ Occupation: money handling & & & & & & $\begin{array}{l}-0.018 \\
(0.066)\end{array}$ & \\
\hline Juvenile delinquency x Occupation: responsibility for other people & & & & & & $\begin{array}{l}-0.000 \\
(0.077)\end{array}$ & \\
\hline Juvenile delinquency x Gender recruiter: male & & & $\begin{array}{l}-0.040 \\
(0.035)\end{array}$ & $\begin{array}{l}-0.036 \\
(0.035)\end{array}$ & $\begin{array}{l}-0.048 \\
(0.038)\end{array}$ & $\begin{array}{l}-0.048 \\
(0.039)\end{array}$ & $\begin{array}{l}-0.045 \\
(0.044)\end{array}$ \\
\hline Juvenile delinquency x Gender recruiter: unknown & & & $\begin{array}{l}-0.033 \\
(0.046)\end{array}$ & $\begin{array}{l}-0.025 \\
(0.046)\end{array}$ & $\begin{array}{l}-0.056 \\
(0.058)\end{array}$ & $\begin{array}{l}-0.053 \\
(0.058)\end{array}$ & $\begin{array}{l}-0.072 \\
(0.065)\end{array}$ \\
\hline Juvenile delinquency x Resume type B & & & & & $\begin{array}{l}0.103^{*} \\
(0.059)\end{array}$ & $\begin{array}{l}0.108^{*} \\
(0.060)\end{array}$ & $\begin{array}{l}0.094 \\
(0.064)\end{array}$ \\
\hline Juvenile delinquency $\mathrm{x}$ First application sent within the pair & & & & & $\begin{array}{l}0.005 \\
(0.059)\end{array}$ & $\begin{array}{l}0.002 \\
(0.059)\end{array}$ & $\begin{array}{l}-0.045 \\
(0.065)\end{array}$ \\
\hline Juvenile delinquency $x$ Number of announced jobs in vacancy & & & & & $\begin{array}{l}-0.020 \\
(0.028)\end{array}$ & $\begin{array}{l}-0.025 \\
(0.030)\end{array}$ & $\begin{array}{l}-0.018 \\
(0.029)\end{array}$ \\
\hline Juvenile delinquency $x \log ($ average number of workers in the firm in 2010) & & & & & & & $\begin{array}{l}0.017 \\
(0.018) \\
\end{array}$ \\
\hline Additional variables: Sector fixed effects in interaction with "juvenile delinquency" & No & No & No & No & Yes & Yes & Yes \\
\hline Observations & 972 & 972 & 972 & 972 & 972 & 972 & 830 \\
\hline
\end{tabular}

Notes: The presented results are linear probability model estimates with positive callback as a dependent variable. The variables that are interacted with "juvenile delinquency" are also included without interaction with this variable. See Section II and Section III for a definition of the variables adopted in the regressions. Standard errors, corrected for clustering at the vacancy level, are in parentheses. $* * *(* *)((*))$ indicates significance at the $1 \%(5 \%)((10 \%))$ level. Except for "juvenile delinquency", all variables are normalised by subtracting their mean among the subpopulation of former juvenile delinquents. The continuous variables are further normalised by dividing by the standard deviation among the subpopulation of former juvenile delinquents. 